\title{
What would potential future opinion leaders like to know? An explorative study on the perceptions of four wood-based innovations
}

\section{Was möchten zukünftige MeinungsbildnerInnen wissen? Eine explorative Studie über die Wahrnehmung von vier holzbasierten Innovationen}

\author{
Lea Ranacher ${ }^{1 *}$, Kathrin Höfferer ${ }^{1}$, Miriam Lettner ${ }^{1}$, Franziska Hesser ${ }^{1}$, Tobias Stern ${ }^{2}$, Romana Rauter ${ }^{2}$, \\ Peter Schwarzbauer ${ }^{3}$
}

\author{
${ }^{1}$ Wood K plus, Market Analysis and Innovation Research Team, Feistmantelstraße 4, 1180 Wien, Austria \\ ${ }^{2}$ University of Graz, Institute of Systems Sciences, Innovation and Sustainability Research, Universitätsplatz 3, 8010 Graz, Austria \\ ${ }^{3}$ University of Natural Resources and Life Sciences Vienna (BOKU), Institute of Marketing and Innovation, Gregor-Mendel-Straße 33, 1180 Wien, \\ Austria \\ * Corresponding author: 1.ranacher@kplus-wood.at
}

Received: 6 February 2018, received in revised form: 17 April 2018, accepted: 27 April 2018

\begin{abstract}
Summary
Wood-based innovations can substantially contribute to bioeconomy and future competitiveness of the forest-based sector. However, the forest-based sector lacks consumer-related information that is essential to achieve societal acceptance and market diffusion of wood-based innovations. Therefore, this study investigates the perceptions and related information demands regarding the four selected innovations, that is, wooden multi-story timber construction (WMC), biorefinery (BR), natural fiber reinforced composites (NFC), and nanocellulose (NC). A focus group discussion with future-oriented individuals representing potential future opinion leaders and a subsequent qualitative content analysis was used as the research method. The results show that the perception and information demand of the focus group participants differs between the innovations as a result of their market maturity. It was observed that the participants discussed WMC, a well-established innovation, in detail compared to NC, a quite recent innovation. The results suggest that the forest-based sector should consider individual and societal benefits when communicating the benefits of wood-based innovations.
\end{abstract}

Keywords: market diffusion, focus groups, content analysis, future-oriented individuals, forest-based sector

\section{Zusammenfassung}

Holzbasierte Innovationen können einen wesentlichen Beitrag zur Bioökonomie im Gesamten und zur zukünftigen Wettbewerbsfähigkeit des Forst-Holz-Sektors im Einzelnen leisten. Allerdings mangelt es dem Forst-Holz-Sektor an konsumentenbezogener Information, die für die gesellschaftliche Akzeptanz und Marktdiffusion von holzbasierten Innovationen notwendig ist. Daher untersucht diese Studie die Wahrnehmung und die damit verbundenen Informationsbedürfnisse von vier ausgewählten Innovationen (mehrstöckiger Holzbau, Bioraffinerien, naturfaserverstärkte Komposite und Nanocellulose). Fokusgruppendiskussionen mit zukunftsorientierten Personen, welche potentielle, zukünftige MeinungsbildnerInnen darstellen, und eine anschließende qualitative Inhaltsanalyse wurden als Methode eingesetzt. Die Ergebnisse zeigen, dass die Wahrnehmung und Informationsbedürfnisse der TeilnehmerInnen zwischen den Innovationen aufgrund ihrer unterschiedlichen Marktreife variieren. Für den mehrstöckigen Holzbau, welcher eine etablierte Innovation darstellt, wurden detailliertere Informationsbedürfnisse erfasst als für Nanocellulose, welche eine relativ neue Innovation darstellt. Die Ergebnisse legen nahe, dass die Kommunikation des Forst-Holz-Sektors die Vorteile von holzbasierten Innovationen auf individueller und gesellschaftlicher Ebene kommunizieren sollte.

Schlagworte: Marktdiffusion, Fokusgruppen, Inhaltsanalyse, zukunftsorientierte Personen, Forst-Holz-Sektor 


\section{Introduction}

Over the last few decades, societal challenges like the global impact of climate change, secured energy supply and reduced energy consumption according to the principles of Sustainable Development as well as the substitution of nonrenewable materials and energy sources with renewable ones have been growing in public awareness (e.g., WCED, 1987; UN, 2015). Maintaining or improving human living conditions without negatively affecting the environment, requires creating and diffusing innovations that address the Sustainable Development Goals (Voegtling and Scherer, 2017). A transition to bioeconomy is one strategy that has been frequently discussed over the last couple of years and offers the chance to reduce dependency from fossil-based resources (e.g., UNECE/FAO, 2016; Patermann and Aguilar, 2018; Ramcilovic-Suominen and Pülzl, 2018). Bioeconomy, as defined in the EU's 2012 Bioeconomy Strategy is “(...) the production of renewable biological resources and the conversion of these resources and waste streams into value added products, such as food, feed, bio-based products and bioenergy" (European Commission, 2012). In this context, the natural resource-based sectors, such as the forest-based sector, are considered to play a vital role by supplying bio-based products and thereby substituting the fossil-based products (Kleinschmit et al., 2014), which enables access to new markets (Roos et al., 2014). This corresponds to the need of the forest-based sector to renew its product and service portfolio to be competitive in the future (Hetemäki et al., 2014; Ollikainen, 2014). Therefore, the political agenda of bioeconomy offers a chance for the forest-based sector to successfully market wood-based innovations whilst contributing to the transition from a fossil-based society towards a bio-based society.

Innovations are new or significantly improved products, processes, or organizational structures (OECD/Eurostat, 2005). According to Schumpeter (1934), innovation is a mechanism that deploys new knowledge, technology, products or services in the market and is in the form of creative destruction, a necessary driver for competitiveness and economic dynamics. However, successfully placing innovations in the market constitutes a substantial challenge and ways to do so has been researched by many scholars (e.g., Schaltegger and Wagner, 2011). One substantial reason for lack of economic success is the absence of societal acceptance as, for example, emerging sustainable energy technologies (Assefa and Frostell, 2007), genetically modified food (Araki and Ishii, 2015) or biofuels (Chin et al.,
2014). However, the increase of societal acceptance of biobased products resulting in a willingness of consumers to pay for these products is central for their diffusion and market penetration (Scarlat et al., 2015).

Wood-based innovations can be considered as so called ecological innovations, eco-innovations or sustainable innovations, which are expected to be beneficial to the natural environment and the economy by reducing waste, emission, or resource use (e.g., Carrillo-Hermosilla et al., 2010). Despite the potential of lower environmental impacts (e.g., Sandin et al., 2016), these innovations can still be rejected by the society and thereby become meaningless (Boons and Lüdeke-Freund, 2013). Therefore, societal acceptance of wood-based innovations is substantial to foster the transition towards bioeconomy and the competitiveness of the forest-based sector. In addition, from the perspective of policy making, the societal perception of wood-based innovations is considered key for the creation and acceptance of bioeconomy strategies.

This study aims at providing first insights on the opinion forming process regarding four different wood-based innovations by future-oriented individuals representing potential future opinion leaders. More precisely, the research questions I) "How are wood-based innovations perceived by potential future opinion leaders?" and II) "What kind of information regarding the potential of wood-based innovations substituting fossil-based products is requested?" will be answered by the focus group discussions with a subsequent content analysis of the data obtained from the discussions. The exploration carried out in this study will provide a base understanding regarding the opinion forming process of the potential future opinion leaders of wood-based innovations in context of their potential in substituting the conventional fossil-based products. This forms a starting point for future research about individual expectations and perceptions towards wood-based innovations. In addition, this will enable the forest-based sector to provide information tailored to the information needs of the potential consumers, which can support the market penetration of the products and thereby support the aims of the bioeconomy strategy.

\section{Conceptual Background}

The success of wood-based innovations is limited as they have not penetrated the markets to the expected extent so far (Clark et al., 2012). For example, despite the potential 
of biorefineries to revitalize the pulp and paper industry, a large-scale implementation of biorefineries is lagging behind (Helsmark and Söderholm, 2017). Furthermore, consumers have shown skepticism and little recognition towards new bio-based products and technologies, like nanocellulose products, composites and building materials (Stern et al., 2018) and market failures lead to inappropriate incentives, which might impede innovations.

Reaching success with material innovations, such as woodbased innovations, is difficult and new products often fail in the market introduction stage despite a good functional performance (Ljungberg and Edwards, 2003). One potential reason is the forest-based sector industries' weak understanding of end-consumer markets, as they are the producers of large quantities, mainly as intermediates in the B2B-markets (Roos et al., 2014). In addition, while the forest-based sector largely focused on technical process innovations like increasing productivity, other issues, such as diversification by business model innovations, for example, product and services, have not been focused on in the past (Hansen, 2006; Stendahl, 2009). How wood-based innovations are perceived, what consumers expect from them and which information demands can be derived thereof, has not yet been thoroughly studied, resulting in a lack of consumer market orientation (Rametsteiner et al., 2006; Hansen and Juslin, 2011). Therefore, researching consumer-related information can contribute to more competitive products and services (Hetemäki et al., 2014) as it supports the adoption and diffusion of innovations. For example, consumer acceptance regarding innovations has been researched in the context of genetically modified foods (Costa-Font et al., 2008) or information technology (Pantano and Di Pietro, 2012). However, in the early phases of technology and innovation development, it is not the adoption of innovations by purchasing them that is relevant yet but the understanding of and support for, for example, wood-based innovations. If opinion leaders perceive such innovations as desirable and worth to pursue, investments in their development and advertisement are made. This, consequently, could then also lead to products and services offered to the end-consumers in respective markets.

In this context, the acceptance and adoption of innovations is closely related to consumer expectation. Rogers' theory "diffusions of innovations", describes the adoption or the acceptance of an innovation as the uptake of an idea, practice, process or product (Rogers, 2003). Usually, an innovation is assessed on its relative advantage compared to actual products, compatibility with existing products or processes, complexity and potential for reinvention (Rogers, 2003). Thus, the perception of wood-based innovation can be strongly influenced by its comparison to a fossilbased counterpart and the expectation regarding its environmental benefit. Consumer expectation can be described as "subjective notions of things to come" (Anderson and Hair, 1972), which affect people's reactions and decisions (Deliza and MacFie, 1996). Consuming the information about an innovation, that is, read or try, results in a certain perception of the innovation among individuals. According to the selection/consumption/re-selection model, a positive response to the expectations will result in consumer's satisfaction followed by a repeated choice of the product with increased expectations for it, whereas negative response will lead to dissatisfaction and rejection of the product and decreased expectations (Deliza and MacFie, 1996). As a result, expectation is strongly related to consumer (dis) satisfaction, which is usually measured in expected and perceived product performance (Anderson 1973).

For new wood-based materials to be successful, consumers need to understand and appreciate the potential material's benefits. Communicating new wood-based innovations' benefits to consumers places great demands on the producers in understanding consumer needs (Ljungberg and Edwards, 2003; Karana et al., 2010). However, the perception of an innovation can vary strongly between individuals and over the course of time (Karana et al., 2010). In the context of wood-based innovations on B2B-markets, Roos et al. (2014) found that different professions of the companies purchasing the innovation have different priorities regarding the material selection. Similarly, potential future opinion leaders have certain expectations regarding wood-based innovations, which are translated into an information demand regarding the performance of the specific innovation.

Many wood-based innovations intended to substitute conventional, fossil-based products are heavily scrutinized regarding their environmental impact (Hesser, 2015). In addition, previous studies found that society can be skeptical regarding the environmental responsibility of the forest-based sector in general (Ranacher and Stern, 2016; Ranacher et al., 2017), which may be considered a potential bottleneck for market diffusion of wood-based innovations. Similarly, Provasnek et al. (2017) argue that eco-innovations face new challenges within the society as they are not always sound with stakeholders' expectation regarding sustainability. Thus, companies are increasingly challenged 
to adapt to numerous, often contradictory societal expectation of their innovations, even if they already have high ecological standards (Provasnek et al., 2017). Thus, perceptions of wood-based innovations are considered to be strongly related to the expectations regarding their environmental performance and may vary significantly between different consumer segments.

\section{Methods and research design}

Within the forest-based sector, bioplastics, composite materials, engineered wood products, and biorefineries were found to be market-ready product or process innovations that are about to, or have already, found a place in the market (Clark et al., 2012). Moreover, a recent study by Stern et al. (2018) surveyed the public perception of wood-based innovations. In this study, innovations like wood-based building systems or construction materials were largely recognized by the general public, whereas composite materials, material substitution, production processes, and biofuels received only medium, and nanocellulose only little recognition (Stern et al., 2018). Based on the findings of these and other studies highlighting the potential of wood-based innovations (Bajpai, 2013; Ekman et al., 2013; Näyhä et al., 2014; Roos et al., 2014; de Assis et al., 2017; Reid et al., 2017), four complementary innovations are taken into account in this study:

- Wooden multi story buildings (WMC) as an example of using an innovative building material such as cross laminated timber

- Natural fiber reinforced composites (NFC) as one example of materials, which can have favorable environmental impacts compared with their counterparts by comparable functional performance

- Nanocellulose (NC) as an example of a wood-based innovation of high expectations and with many potential future applications, such as composites or packaging (Eichhorn et al., 2009)

- The concept of biorefinery (BR), as the sustainable processing of biomass into a spectrum of marketable products and energy substituting fossil resources, of which the lignocellulosic biorefinery is considered to have the biggest market potential.

This explorative qualitative study applies focus group discussions with a subsequent content analysis in order to gather systematic information on how the selected wood- based innovations (NFC, WMC, NC, and BR) are perceived and what further information is requested by the focus group participants.

According to Krueger and Casey (2009), focus groups are a group of individuals who are selected by researchers to have a discussion on a subject of research based on their personal experience. The procedure is practically well suited to check or generate theses or ideas and is used especially for obtaining information about attitudes of certain target groups in a qualitative way, which is considered to be an appropriate method in the field of environment and sustainability research (Henseling et al., 2006). The focus groups were conducted as proposed by Morgan (1998).

Participants were selected through convenience sampling. People were invited by a short text explaining the purpose of the study and organizational key facts (dates, place, time). The invitation was distributed using the personal networks of the researchers addressing friends and colleagues from the University of Natural Resources and Life Sciences, Vienna, and thereby targeting a sample with high level of education and interest in environmental issues and aged $20-40$ years. These characteristics are expected to indicate future-oriented individuals representing potential future opinion leaders.

To assess the future orientation of the participants they had to answer a questionnaire about their consideration of future consequences (CFC) (Strathman et al., 1994) before participating in the focus group. The CFS is a survey instrument to assess the extent to which people emphasize short-term or long-term consequences of their behavior. A high score (max. 50) indicates a focus on the future implications of a behavior, whereas a low score (min. 10) indicates a focus on current needs and concerns (Strathman et al., 1994). Furthermore, the questionnaire contained a module on socio-demographic features to characterize the sample.

In total, four focus group discussions with four to six participants each were carried out (Table 1). Out of the 20 participants, 13 were male $(65 \%)$ and the total average age was 27 years. 55\% had a bachelor's degree and 30\% a master's degree as the highest level of education. $60 \%$ of the participants had lived most of their life in a suburb and city or urban area, and $45 \%$ stated that they are involved in the forest-based sector due to formal education or profession. On the CFC scale, the focus groups scored between 27 and 41, reflecting a medium to high future orientation. A set of four information cards for each innovation was supplied as stimuli at the beginning of each focus group 
discussion. Each information card contained a short paragraph on the manufacturing process, benefits, characteristics, or scope of application of the four selected innovations ( 4 times 4 cards). All participants had to pick two cards that appeared most interesting to them. The main purpose of this was to have a starting point for discussion and to see which kind of information and which innovations were preferably chosen. Then, the moderator, one of the authors of the study, started the discussion asking questions like "Why did you choose this card?", "Why did you mention (...)?" "What do you mean by (...)?” to start the discussion. In each focus group, all four previously described innovations were discussed. The moderator encouraged the participants to talk about the issues raised in the discussions by using the questions above; however, people were not forced to give statements, and therefore, a balance between the different innovations could not be achieved. All focus groups took around 90 minutes.

All the focus group discussions were audio recorded and transcribed. The transcripts were analyzed with a qualitative content analysis (Mayring, 2003) performed with the software MAXQDA. First a deductive coding scheme based on the information card categories (i.e., manufacturing process, benefits, characteristic, or application) was applied. Second, an inductive coding scheme was created to organize the data according to topics that evolved through the material. In both cases, a summarized content analysis was used that aims at reducing the transcript material in a way, so that the essential content still remains (Mayring, 2003). Codes were generated based on the text material and organized the statements made in the discussions. The unit of analysis for coding ranged from a single sentence to a whole paragraph. The given codes were then assorted to categories, representing the topics discussed in the focus groups. First, the frequency of these categories occurring in the discussions was counted to make a statement about which topics are discussed in which intensity. Second, the most discussed topics for each innovation are described to provide an insight about the main areas of interest regarding the four innovations. Thus, this analysis follows a quantitative and qualitative approach.

\section{Results}

\subsection{Selection of cards}

In addition to the qualitative approach in this study, the frequency by which the information cards were picked, provides insight into which innovations and which information were appealing to the participants. The participants were asked to choose two information cards each. Therefore, the number of cards picked in each round depends on the size of the focus group. Each card could only be picked once. In the four focus groups sessions, between 8 and 12 cards were picked, resulting in an average of 10 cards. Figure 1 shows that across all innovations and focus groups sessions, the information card "Benefits" was chosen most frequently (14 times), followed by "Manufacturing Process" and "Scope of Application" (both 9 times), and "Characteristics" (8 times). Across all focus group sessions, most cards selected pertained to WMC (13 times), followed by BR (10 times), NC (9 times), and NFC (8 times). Thus, the participants showed most interest for the benefits of innovations as well as multi-story timber construction. However, the differences between the given innovations are smaller than the differences between the given types of information.

\subsection{Analysis of focus group discussions}

Based on the previously described content analysis, 15 categories or topics, were identified and are given in Figure 2. The topics costs, environmental studies, material, and potential were discussed for all innovations, whereas some topics were only discussed for some innovations. The topic

Table 1. Overview of focus groups

Tabelle 1. Übersicht über die Fokusgruppen

\begin{tabular}{|c|c|c|c|}
\hline Focus group & Number of participants & Place and Date & Level of future orientation (CFC Scale) \\
\hline 1 & 6 & Vienna, 22 $2^{\text {nd }}$ July, 2015 & 27 \\
\hline 2 & 4 & Vienna, $30^{\text {th }}$ July, 2015 & 36 \\
\hline 3 & 5 & Vienna, 31 July, 2015 & 30 \\
\hline 4 & 5 & Vienna, $7^{\text {th }}$ August, 2015 & 41 \\
\hline
\end{tabular}




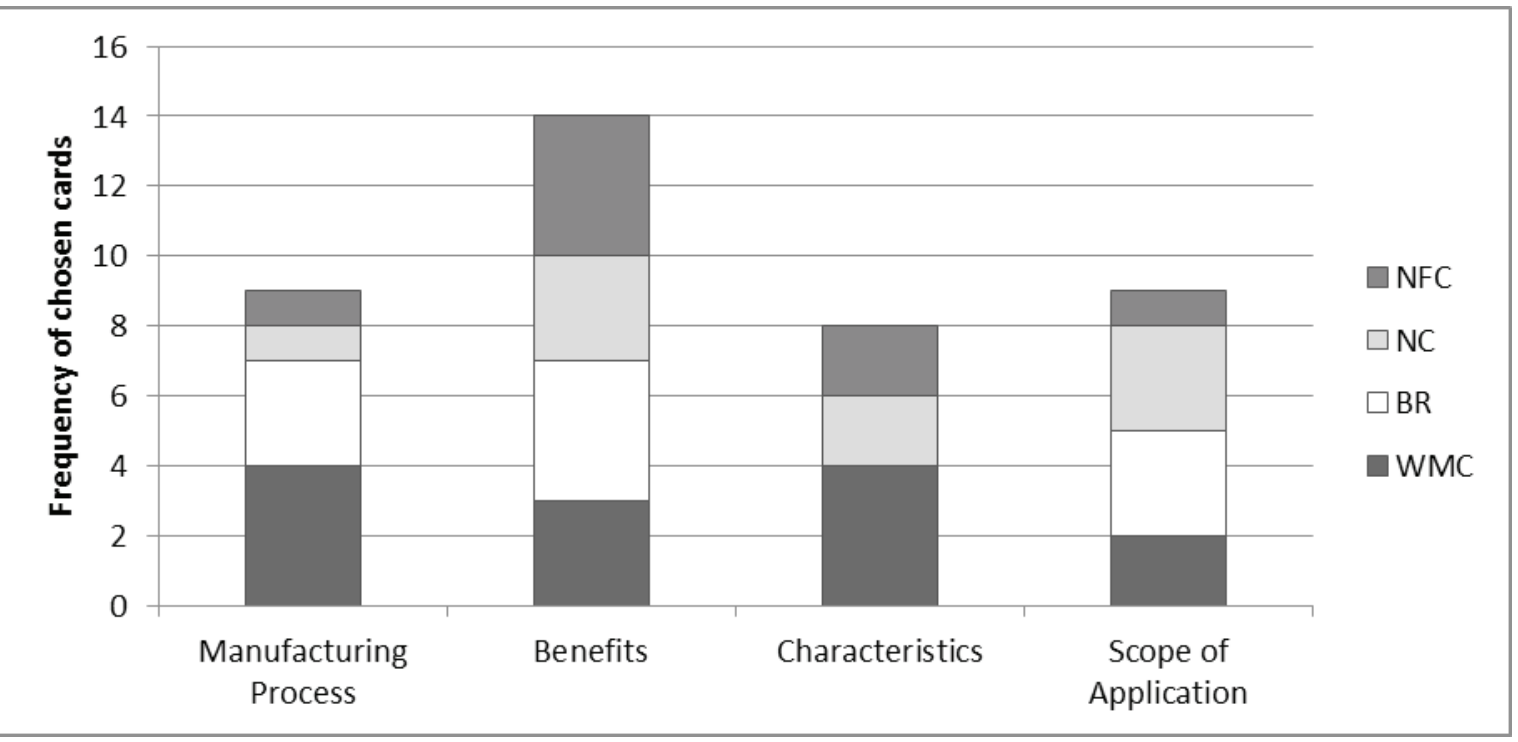

Figure 1. Frequency of the chosen cards by type of information and innovations in absolute numbers. NFC = natural fiber reinforced composites, $\mathrm{NC}=$ nanocellulose, $\mathrm{BR}=$ biorefinery, $\mathrm{WMC}=$ wooden multi-story timber construction

Abbildung 1. Häufigkeit der ausgewählten Karten nach Informationstyp und Innovationen in absoluten Zahlen. NFC = naturfaserverstärkte Komposite, $\mathrm{NC}=$ Nanocellulose, $\mathrm{BR}=$ Bioraffinerie, $\mathrm{WMC}=$ mehrstöckiger Holzbau

of costs mainly referred to issues such as the costs regarding the manufacturing process and whether the use of biobased materials is cheaper or more expensive than using fossil-based materials. The topic of environmental studies centered around the studies to estimate consequences on human and environmental health. The topic material addressed questions regarding the kind of bio-based material used for the innovations as well as its origin (e.g., domestic or foreign). The topic potential addressed issues related to the innovation's potential to substitute fossil-based product and related economic viability.

As Figure 2 depicts that the intensity with which the topics were discussed (measured in frequencies) is not equally distributed among all four innovations, indicating the demand of different areas of information regarding the respective innovation. Thus, in the chapters below, the most frequently discussed topics are described for each innovation, indicating the major areas of concern for each innovation.

\subsubsection{Wooden multi-story timber construction}

Generally speaking, WMC accounts for the most positive perception among the participants. All the participants associate timber constructions with high-quality wood features. Reasons to favor timber over concrete or steel constructions were the positive aspects attached to wood such as health effects as well as societal benefits regarding climate change mitigation. For WMC, 11 different topics were discussed, which in total received 148 hits making it the most discussed innovation. The participants mainly discussed about safety, costs, and ecological aspects regarding the material, in comparison to concrete and steel constructions.

Safety: Almost all respondents could picture themselves living in a multi-story timber construction as long as it was as safe as concrete and steel constructions. Frequently mentioned issues about the multi-story timber construction were mostly concerns about the stability as well as static challenges. Information requests concerning the security of timber constructions appeared in all four focus groups. In this context, the respondents further mentioned possible danger through moisture, rot, fire, mold or termite damage. The participants were further interested in facts about the technical possibilities, not just regarding height, but they wondered if certain things are actually possible, like a rooftop pool or an open fireplace. Overall, the participants expressed concerns regarding safety and the capability of timber constructions in comparison to concrete, as for example: "Well I think [...], that concrete constructions gained more experience and have already proved its worth. Also, the statistical computation concepts are easier to develop. While I'm not sure, if multi-story timber constructions are easy and straight forward to apply in practice."

Costs: Maintenance and manufacturing costs were also frequently mentioned during the discussions. For example, almost all participants doubted that the external 


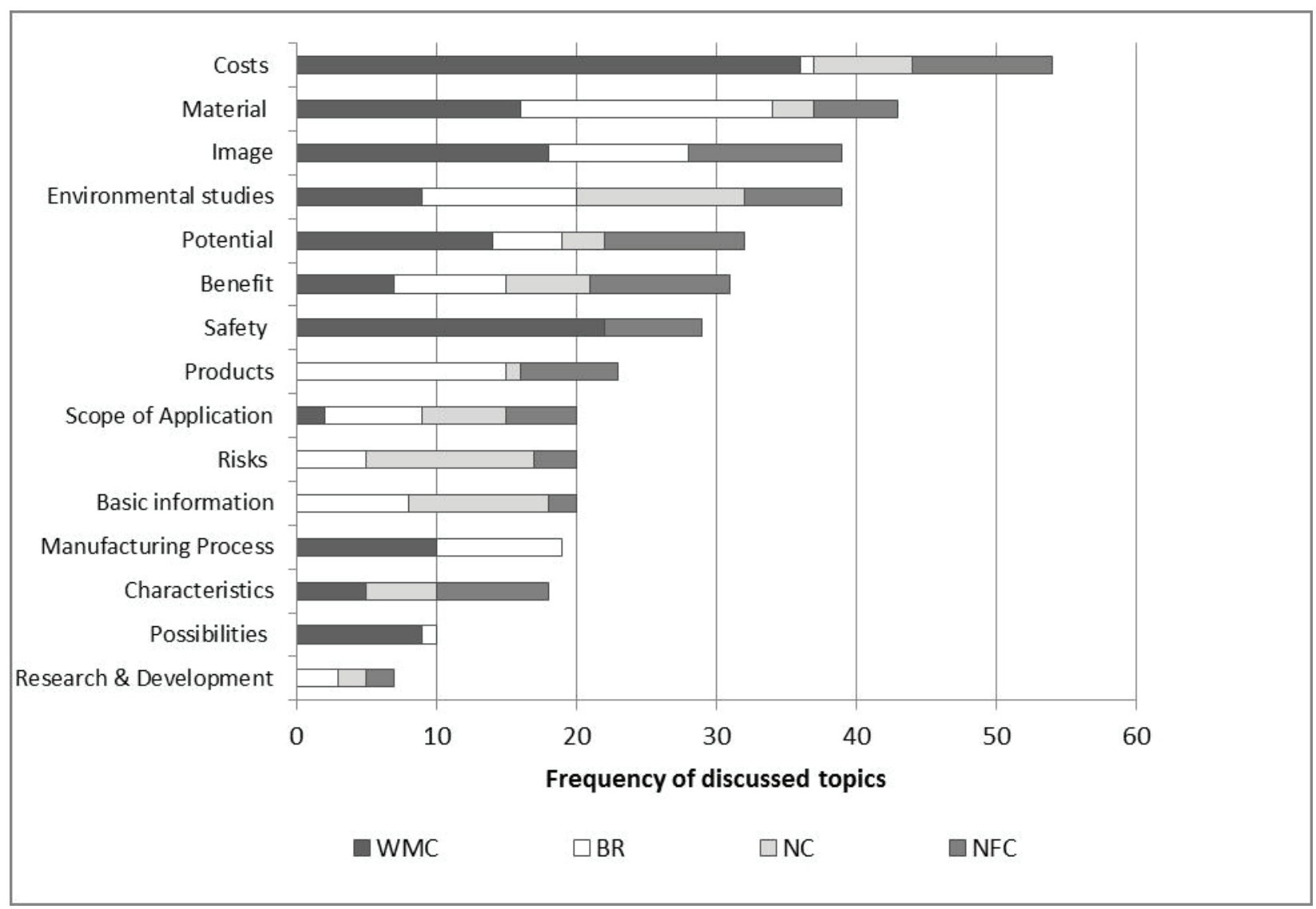

Figure 2. Overview of topics identified in the focus group discussions in absolute numbers. WMC = wooden multi-story timber construction, $\mathrm{BR}=$ biorefinery, $\mathrm{NC}=$ nanocellulose, $\mathrm{NFC}$ = natural fiber reinforced composites

Abbildung 2. Übersicht über die Themen die in den Fokusgruppendiskussionen identifiziert wurden in absoluten Zahlen. WMC = mehrstöckiger Holzbau, $\mathrm{BR}=$ Bioraffinerie, $\mathrm{NC}$ = Nanocellulose, NFC = naturfaserverstärkte Komposite

facade will stand the weather and temperatures that is considered to result in high maintenance costs. However, high costs are considered to be balanced by other benefits such as reduced heating cost or overall climate mitigation benefits, as illustrated in the following quote: "Except that timber constructions probably show high maintenance costs, I think that they are way better when it comes to heating and climate."

Material: Participants raised questions regarding the material used for multi-story timber constructions. Next to the technical material characteristics required for WMC, the participants were interested in the geographical origin of the material. They mentioned it was important for them that the timber is from domestic, or in exceptional cases from the European forests. Furthermore, they were interested in environmental studies like carbon footprint analysis. Particular interest was in a comparison of conventional construction and multi-story timber constructions concerning their eco-compatibility. The participants consider timber construction as highly relevant to reduce the use of fossil-based materials: "I think timber has the ability to change the construction industry. In former times, houses have been built in a conventional way with reinforced concrete, brick and suchlike; timber becomes more and more significant for the construction industry."

\subsubsection{Biorefinery}

BR was perceived as a very interesting, sustainable opportunity to counteract the depletion of fossil-based resources, although only little knowledge exists amongst the participants. Main points of discussion were about the feedstock that is used, basic knowledge regarding the products, and environmental issues related to the use of these innovations. For BR, 13 topics were identified, which received 101 hits. Required information was mostly due to feedstock (biomass) origin, comparable with wood-construction; although compared to that the knowledge was rather uncertain, leading to the need of more basic information on the concept. Additionally, not only the high relevance of environmental studies on BR products, but also informa- 
tion demand on the process itself occurred. The demand of having accompanying assessments for innovative processes and products is an important approach to achieve sustainable and competitive products in line with the vision of future knowledge based bioeconomy.

Material: Main interest was attributed to the question about the varying products that can be manufactured by a $\mathrm{BR}$ and which conventional products could be substituted by them. In this context, questions have been raised about what kind of feedstocks can be used for the manufacturing process and if this would lead to an increase or decrease in the product quality. The participants totally support the idea of using wood residuals, organic waste or other available biogenic residues but reject the cultivation of grain, energy wood or food crops for this purpose: "I think this is a good idea as long as only residues are used instead of biomass grown specifically for this purpose."

Basic information: When asked about the purpose of a $\mathrm{BR}$, only a few participants were able to answer this question. Still, almost all the respondents showed high interest in the innovation although the participants admitted a lack of basic knowledge about BR. Although, there is only little knowledge, participants value the innovation as a promising technology and attribute high potential to it in the near future, illustrated here: "Exactly, biorefinery is a rather unknown topic, but an exciting one though, probably with high potential in future."The respondents further considered it as highly important to inform the general public about the innovation: "Yes, it is very important to give information about the innovation, especially to inform the general public. However, I agree, saying that studies about certain innovations have to be transparent and independent."

Environmental studies: Topics like the product life cycle and the recycling process were also mentioned a few times. For example, the respondents questioned if products manufactured by a BR are fully recyclable or biodegradable. The participants stated that it is important to conduct environmental and economic analysis of BR, especially regarding the recyclability of the products. One participant mentioned an interesting comparative example, which was considered as a good exemplary presentation for the public: "It would be very interesting how much biomass I would need for manufacturing the same amount of a certain product made of petrol?"

\subsubsection{Natural fiber reinforced composites}

The innovation was discussed controversially among the participants. Most of the participants are already familiar with this innovation or have at least heard about NFCs. Some participants associated NFCs as a lightweight construction and packaging material used in the automotive industry. However, questions regarding further applications of NFCs were raised. For NFC, 13 topics were identified that received 88 hits in total. The most discussed topics were costs, possible applications, and ecological issues regarding the recycling capability.

Costs: Costs were frequently discussed when comparing natural fiber composites with conventional plastic. Some of the respondents considered this innovation as cheaper than conventional products. Respondents pointed out that as long as natural fiber composites are not more expensive than conventional products, the innovation is a serious alternative to some fossil-based products. Some of the respondents attributed a high potential to the innovation whereas others in turn did not see the purpose of the innovation at all and questioned its economic feasibility. Participants further argued that as long as NFCs contain more conventional plastic than natural fibers, it does not make sense to produce it: "As far as I know, natural fiber composites just contain 20 percent of natural fiber but 80 percent of plastic."

Application: The participants acknowledge the benefit of the innovation concerning its technical properties, the broad range of applications as well as the technology progress in the construction and automotive sector. In contrast, risks regarding the durability and resistance of NFC have also been raised. Some participants wanted to know which products could be produced from natural fiber composites and were impressed of the technical capabilities of the material: "I generally consider it as highly interesting, composite materials still have the potential to break records. Just look at, whatever [...] years ago certain standards existed, whether it was in the construction industry or in engineering area, wherever, the more composite materials were developed, the easier and efficient it was to build and construct or repair things."

Environmental studies: Participants were interested in the durability of the products and if NFCs are biodegradable. One respondent mentioned that if there is too much "chemistry" used during the manufacturing process, the whole innovation loses its connection to nature. Respondents stated that petrochemical based products to be substituted by NFC could also be replaced by any other biomaterial. Examples provided were stone, wood, ceramic or rubber. Some believed that the innovation just exists because of its excellent marketing. "The whole topic is not 
my favorite. This material has been around for such a long time, but it never was really successful... so... whatever." One participant considered it as very strange to associate one of the major green-house gas emitter - the private transport with sustainability: "Well, maybe it is because they promote it under the aspect of sustainability. Fossil resources are depleting but to associate wood-based innovations with cars in the same way sounds weird to me; to furnish the biggest contributor of greenhouse gas emissions with sustainability?”

\subsubsection{Nanocellulose}

This innovation was hardly known among the participants, which might be a reason why the level of interest was relatively low. Almost none of the respondents had ever heard of NC before. The participants often indicated that their statements were based on guessing. For NC, 11 topics were identified, which received 67 hits, making it the least discussed innovation in the focus groups. The most discussed topics regarding $\mathrm{NC}$ were basic information, risks, and environmental studies.

Basic information: Basically, all the participants asked for more information about $\mathrm{NC}$ and further mentioned that the innovation is probably too complex to be comprehensively communicated to a general audience. This was in particular mentioned in context to the manufacturing process: "How is it produced, what is this, what can people do with it?"

Risks: Most participants questioned were the benefits in relation to potential risks, going along with nano-technology, on humans, animals and the environment. Also, the respondents had no imagination about the possible area of application or what kind of products NC could substitute. Basic knowledge was almost completely missing; yet, the respondents could imagine that NC might have a promising future since nanotechnology might be a huge improvement for different fields. "Investigating further research might be highly interesting. In my opinion important for the scope of application are risks, advantages and disadvantages."

Environmental studies: Associations with NC related strongly to health risks and effects on the environment. Long-term studies were highly desirable by almost all participants. The respondents also mentioned their worries about the possible presence of $\mathrm{NC}$ in food and the food chain. "Well ... it exists and it is in use, but many effects are maybe not known yet... in the broadest sense, nobody knows what will happen in future ... the topic is interesting but problematic in the same way though."

\section{Discussion and conclusion}

The forest-based sector lacks communication of relevant information for individuals; however, such information is considered essential for societal acceptance in general, and thus, successful market diffusion of wood-based innovations in particular. Therefore, this study investigated the perceptions and related information demands of potential future opinion leaders of the four selected wood-based innovations supporting the transition towards bioeconomy. Regarding the provided information categories in the introduction round, the results indicate that participants appeared to be slightly more interested in the benefits of innovations in comparison to the manufacturing process, scope of application or characteristics. An explanation for this preference could be that both issues are more closely related to their personal lives (i.e., How do I benefit from that?). This is in line with a recent study by Sijtsema et al. (2016), which found that once consumers are confronted with bio-based products, their evaluation of the technology is based in the context of personal benefits. The results further show that the topics costs, environmental studies, material origin, and future potential were discussed for all four innovations. This indicates that participants are specifically interested in the economic and environmental aspects of wood-based innovations. Again, this is in line with Sijtsema et al. (2016), who showed that consumers often have environment-related associations when discussing bio-based products and processes and consider price as an important aspect. Thus, on a general level, the results suggest that the potential future opinion leaders demand information about wood-based innovations, particularly regarding the economic benefits (e.g., costs) and environmental aspects (e.g., consequences on human and environmental health).

Furthermore, how the innovations were discussed varies by quantity and quality. First, the four selected innovations were discussed at different levels of intensity measured in the frequency hits. WMC was discussed the most, followed by BR, NFC, and NC. Similarly, in the introductory round, the information card on WMC was picked more often in comparison to the other innovations. An explanation for this could be the stronger recognition of WMC (i.e., I have seen timber construction in real life and can relate to it.). This explanation would be partly consistent with the "cognitive response theory" (Greenwald, 1968), which attempts to understand how people acquire and process information. If the respondents received new information, they select it 
according to their pre-existing thoughts and personal stories they had already heard about the innovation. Second, the discussed topics varied between the innovations that provided insight into the perception and information demand regarding the selected wood-based innovations. For WMC, safety, costs, and material were the dominant issues whereas for $\mathrm{NC}$ basic information, risk and environmental studies were the central issues. This is in line with a study carried out by Siegrist et al. (2008), which focused on the perceived risks and benefits of different products and the applications of nanotechnology, showing that affect and perceived control are important factors on the perception of nanotechnology packaging material. Hence, the results suggest that an innovation is discussed in more detail if previous knowledge regarding the innovation already exists, as it was the case for WMC. Furthermore, the results suggest that the lower the level of awareness, the more strongly the information demand is related to fears and concerns associated with the innovation.

As Deliza and MacFie (1996) argue that innovations are judged based on the comparison of one's expectation with the actual perception. The level of congruency between expectation and perception influences the level of acceptance (rejection or approval). The results propose that these comparisons can be made on an individual (e.g., technical, commercial) or societal (e.g., environment, economy) level. The results suggest that the more well-known innovations are rather judged on individual level (i.e., personal costs and benefits) than the less-known innovations (i.e., societal costs and benefits). Hence, to communicate the benefits of wood-based innovations, contextual information on individual or societal level is required. This could be due to the fact that the perception of innovations is often accompanied by a hype, a phase characterized by an upsurge of public attention and high rising expectations about the potential of the innovation (Ruef and Markard, 2010). Such hypes are, according to the Gartner hype cycle concept (Fenn, 2006; Fenn and Raskino, 2008), followed by a considerable decline of attention that may be connected with disappointment of the earlier expectations. Thus, it is conclusive that early innovations that are barely visible are accompanied of little expectations (NC), whereas innovations with early maturity and strong visibility have high expectations (BR) and these expectations decrease (NFC), and after being established at the market have a solid level (WMC). However, as companies are increasingly challenged to adapt to numerous, often contradictory societal expectations of their innovations (Provasnek et al., 2017), communicating the benefits to potential future opinion leaders at individual or societal level could result in conflicting messages, especially when considering different consumer segments.

It is noteworthy that this study only considered the participants' perceptions and information demands, not their actual consumption behavior regarding wood-based innovations, since the research did not take into account the participants' commercial or technical acceptance of the respective categories of innovations. Furthermore, the participants already had some perception of the innovation, for example, through news media or personal experience. Therefore, the focus group discussion depicts the expectation, the perception as well the information demand regarding the innovation. The expectation of the elements, resulting information demand and perception cannot be described separately from each other. For this, a separate study would be necessary. Furthermore, it is noteworthy that the study is limited due to the sample. Half of the sample is involved in the forest-based sector which is considered to have a positive impact on the perception of innovations. A study with individuals without any relationship to the sector might lead to different results. Furthermore, a sample resulting from the personal networks of the authors might be biased. However, the sample represents individuals with a strong educational background and environmental interest, and therefore, are considered suitable for the purpose of this study.

Acknowledging the drawbacks of the study, the results provide a snapshot regarding the perception and information demand of four wood-based innovations by potential future opinion leaders. We conclude that to communicate the benefits of wood-based innovations, economic and environmental aspects in comparison to conventional products should be addressed. However, depending on the level of awareness, this information should address the societal or individual expectations. Furthermore, the potential benefits of innovations may be a trigger for people to decide on future information demand. Even if innovations are not typical consumer goods, people are interested in costs. People are in general skeptical regarding bio-based innovations by questioning costs, environmental impacts and risks.

\section{Acknowledgements}

The study was funded under the Wood Wisdom era-net co-financed by the Austrian Federal Ministry of Agricul- 
ture, Forestry, Environment and Water Management under grant agreement 101002/1 and the Austrian Research Promotion Agency (FFG) under the COMET program grant number 844608 .

\section{References}

Anderson, R.E. and J.R. Hair (1972): Consumerism, consumer expectations, and perceived product performance. In: Venkatesan, M. (Ed.): Proceedings of the Third Annual Conference. Association for Consumer Research, Iowa City, USA.

Anderson, R.E. (1973): Consumer dissatisfaction: The effect of disconfirmed expectancy on perceived product performance. Journal of Marketing Research 10, 3844.

Araki, M. and T. Ishii (2015): Towards social acceptance of plant breeding by genome editing. Trends in Plant Science 20, 145-149.

Assefa, G. and B. Frostell (2007): Social sustainability and social acceptance in technology assessment: A case study of energy technologies. Technology in Society 29, 63-78.

Bajpai, P. (2013): Biorefinery in the Pulp and Paper Industry. Academic Press, London, UK, 114 pp.

Boons, F. and F. Lüdeke-Freund (2013): Business models for sustainable innovation: State-of-the-art and steps towards a research agenda. Journal of Cleaner Production 45, 9-19.

Carrillo-Hermosilla, J., del Río, P. and T. Könnölä (2010): Diversity of eco-innovations: Reflections from selected case studies. Journal of Cleaner Production 18, 10731083.

Clark, D., Aurenhammer, P., Bartlomé, O. and M. Spear (2012): Innovative wood-based products, 2011-2012. In: UNECE/FAO (Ed.): Forest Products Annual Market Review, 2011-2012. United Nations Economic Commission for Europe and Food and Agriculture Organization of the United Nations, New York and Geneva, 141-150.

Costa-Font, M., Gil, J.M. and W.B. Traill (2008): Consumer acceptance, valuation of and attitudes towards genetically modified food: Review and implications for food policy. Food Policy 33, 99-111.

Deliza, R. and H.J.H. MacFie (1996): The generation of sensory expectation by external cues and its effect on sensory perception and hedonic ratings: A review. Journal of Sensory Studies 11, 103-128.

de Assis, C.A., Houtman, C., Phillips, R., Bilek, E.M., Rojas, O.J., Pal, L., Peresin, M.S., Jameel, H. and R. Gonzalez (2017): Conversion economics of forest biomaterials: Risk and financial analysis of CNC manufacturing. Biofuels, Bioproducts and Biorefining 11, 682-700.

Eichhorn, S.J., Dufresne, A., Aranguren, M., Marcovich, N.E., Capadona, J.R., Rowan, S.J., Weder, C., Thielemans, W., Roman, M. and S. Renneckar (2009): Review: Current international research into cellulose nanofibres and nanocomposites. Journal of Materials Science 45, 1.

Ekman, A., Campos, M., Lindahl, S., Co, M., Börjesson, P., Karlsson, E.N. and C. Turner (2013): Bioresource utilisation by sustainable technologies in new valueadded biorefinery concepts - Two case studies from food and forest industry. Journal of Cleaner Production 57, 46-58.

European Commission (2012): Innovating for Sustainable Growth: A Bioeconomy for Europe. http://ec.europa. eu/research/bioeconomy/pdf/official-strategy_en.pdf Accessed on 7 February 2018.

Fenn, J. (2006): Understanding Gartner's hype cycles. Gartner Inc., Stanford, USA.

Fenn, J. and M. Raskino (2008): Hype Cycle Winners and Losers. In: Fenn, J. and M. Raskino (Eds.): Mastering the Hype Cycle: How to Choose the Right Innovation at the Right Time. Harvard Business School Press, Harvard, USA, pp. 3-24.

Greenwald, A.G. (1968): Cognitive Learning, Cognitive Response to Persuasion, and Attitude Change. Academic Press Inc, New York, USA.

Hansen, E. (2006): Structural panel industry evolution: Implications for innovation and new product development. Forest Policy and Economics 8, 774-783.

Hansen, E. and H. Juslin (2011): Strategic marketing in the global forest industries. $2^{\text {nd }}$ ed., Authors Academic Press, Corvallis, Oregon, USA, 327 pp.

Hellsmark, H. and P. Söderholm (2017): Innovation policies for advanced biorefinery development: Key considerations and lessons from Sweden. Biofuels, Bioproducts and Biorefining 11, 28-40.

Henseling, C., Hahn T. and K. Nolting (2006): Instrument in der Umwelt- und Nachhaltigkeitsforschung. Werkstatt Bericht Nr. 82, Berlin, Deutschland. 
Hemström, K., Mahapatra, K. and L. Gustavsson (2014): Public perceptions and acceptance of intensive forestry in Sweden. Ambio 43, 196-206.

Hesser, F. (2015): Environmental advantage by choice: Exante LCA for a new Kraft pulp fibre reinforced polypropylene composite in comparison to reference materials. Composites Part B: Engineering 79, 197-203.

Hetemäki, L., Hoen, H. and P. Schwarzbauer (2014): Conclusions and policy implications. In: Hetemäki, L. (Ed.): Future of the European Forest-Based Sector: Structural Changes Towards Bioeconomy. What Science Can Tell Us 6, European Forestry Institute, pp. 95-108.

Karana, E., Hekkert, P. and P. Kandachar (2010): A tool for meaning driven materials selection. Materials \& Design 31, 2932-2941.

Kleinschmit, D., Lindstad, B.H., Thorsen, B.J., Toppinen, A., Roos, A. and S. Baardsen (2014): Shades of green: A social scientific view on bioeconomy in the forest sector. Scandinavian Journal of Forest Research 29, 402-410.

Krueger, R.A. and M.A. Casey (2009): Focus Groups. A Practical Guide for Applied Research. $4^{\text {th }}$ ed., Sage Publications, Thousand Oaks, California.

Ljungberg, L.Y. and K.L. Edwards (2003): Design, materials selection and marketing of successful products. Materials \& Design 24, 519-529.

Mayring, P. (2003): Qualitative Inhaltsanalyse: Grundlagen und Techniken. 8. Aufl., Beltz UTB, Weinheim, Deutschland.

Morgan, D.L. (1998): The Focus Group Guidebook. Sage Publications, Tousand Oaks, California.

Näyhä, A., Hetemäki, L. and T. Stern (2014): New products outlook. In: Hetemäki, L. (Ed.): Future of the European Forest-Based Sector: Structural Changes Towards Bioeconomy. What Science Can Tell Us 6, European Forestry Institute, pp. 43-54.

OECD/Eurostat. (2005): Oslo Manual: Guidelines for Collecting and Interpreting Innovation Data. OECD Publishing, Paris.

Ollikainen, M. (2014): Forestry in bioeconomy - Smart green growth for the humankind. Scandinavian Journal of Forest Research 29, 360-366.

Pantano, E. and L. Di Pietro (2012): Understanding consumer's acceptance of technology-based innovations in retailing. Journal of Technology, Management \& Innovation $7,1-19$.

Patermann, C. and A. Aguilar (2018): The origins of the bioeconomy in the European Union. New Biotechnology 40, 20-24.
Provasnek, A.K., Sentic, A. and E. Schmid (2017): Integrating Eco-Innovations and Stakeholder Engagement for Sustainable Development and a Social License to Operate. Corporate Social Responsibility and Environmental Management 24, 173-185.

Ramcilovic-Suominen, S. and H. Pülzl (2018): Sustainable development - A 'selling point' of the emerging EU bioeconomy policy framework? Journal of Cleaner Production 172, 4170-4180.

Ranacher, L., Lähtinen, K., Järvinen, E. and A. Toppinen (2017): Perceptions of the general public on forest sector responsibility: A survey related to ecosystem services and forest sector business impacts in four European countries. Forest Policy and Economics 78, 180-189.

Ranacher, L. and T. Stern (2016): Are your messages being heard? Evaluation of the forest-based sector's communication on sustainable forest management in Austria. Jahrbuch der Österreichischen Gesellschaft für Agrarökonomie, Band 25, 159-168.

Rametsteiner, E., Hansen, E. and A. Niskanen (2006): Introduction to the special issue on innovation and entrepreneurship in the forest sector, Forest Policy and Economics 8, 669-673.

Reid, M. S., Villalobos, M. and E.D. Cranston (2017): Benchmarking Cellulose Nanocrystals: From the Laboratory to Industrial Production. Langmuir 33, 15831598.

Rogers, E.M. (2003): Diffusion of Innovations. $5^{\text {th }}$ ed., Free Press, New York, USA.

Roos, A., Lindström, M., Heuts, L., Hylander, N., Lind, E. and C. Nielsen (2014): Innovation diffusion of new wood-based materials - reducing the "time to market". Scandinavian Journal of Forest Research 29, 394-401.

Ruef, A. and J. Markard (2010): What happens after a hype? How changing expectations affected innovation activities in the case of stationary fuel cells. Technology Analysis \& Strategic Management 22, 317-338.

Sandin, G., Peters, G.M. and M. Svanström (2016): Life Cycle Assessment of Forest Products. Springer International Publishing, Cham, Switzerland.

Scarlat, N., Dallemand, J.F., Monforti-Ferrario, F. and V. Nita (2015): The role of biomass and bioenergy in a future bioeconomy: Policies and facts. Environmental Development 15, 3-34.

Schaltegger, S. and M. Wagner (2011): Sustainable entrepreneurship and sustainability innovation: Categories and interactions, Business Strategy and the Environment 20, 222-237. 
Schumpeter, J. (1934): The theory of economic development. Harvard University Press, Harvard, USA.

Siegrist, M., Stampfli, N., Kastenholz, H. and C. Keller (2008): Perceived risks and perceived benefits of different nanotechnology foods and nanotechnology food packaging. Appetite 51, 283-290.

Sijtsema, S.J., Onwezen, M.C., Reinders, M.J., Dagevos, H., Partanen, A. and M. Meeusen (2016): Consumer perception of bio-based products - An exploratory study in 5 European countries. NJAS - Wageningen Journal of Life Sciences 77, 61-69.

Stendahl, M. (2009): Management of product development projects in the wood industry. Scandinavian Journal of Forest Research 24, 434-447.

Strathman, A., Gleicher, F., Boningner, D. and S. Edwards (1994). The consideration of future consequences: Weighting immediate and distant outcomes of behaviour. Journal of Personality and Social Psychology 66, 742-752.
Stern, T., Ranacher, L., Mair, C., Berghäll, S., Lähtinen, K., Vihakara, M. and A. Toppinen (2018): Perceptions on the future importance of forest sector innovations: biofuels, biomaterials or niche products? Forests 9, 255.

UNECE/FAO (2016): Forest Products Annual Market Review 2015-2016 https://www.unece.org/fileadmin/ DAM/timber/publications/fpamr2016.pdf Accessed on 7 February 2018.

UN (2015): Transforming our world: the 2030 Agenda for Sustainable Development. UN General Assembly 21st October 2015. http://www.un.org/ga/search/view_doc. asp? symbol=A/RES/70/1\&Lang=E. Accessed on 2 February 2018.

Voegtling, C. and A.G. Scherer (2017): Responsible innovation and the innovation of responsibility: Governing sustainable development in a globalized world. Journal of Business Ethics 143, 227-243.

WCED (1987): Our Common Future. Oxford University Press, Oxford, UK, 400 pp. 